\title{
Pharmaceutical, pharmacokinetic and other considerations for intravenous to oral stepdown therapy
}

PETER J JEWESSON BSC(Pharm) PhD(Pharm Sciences) FCSHP

\begin{abstract}
PJ Jewesson. Pharmaceutical, pharmacokinetic and other considerations for intravenous to oral stepdown therapy. Can $\mathbf{J}$ Infect Dis 1995;6(Suppl A):11A-16A. Parenteral to oral stepdown therapy represents an effective cost containment strategy which can minimize intravenous therapy associated morbidity and may facilitate earlier hospital discharge. Several oral anti-infectives are available to the prescriber and there are as many opportunities to stepdown to the same agent as there are to other drugs of the same class or other classes. Recognition of the pharmacokinetic characteristics of these oral agents is essential to successful therapy. Good bioavailability may not always be assured. A simple regimen will promote compliance.
\end{abstract}

Key Words: Anti-infectives, Intravenous agents, Oral agents, Stepdown

\section{Considérations pharmaceutiques, pharmacocinétiques et autres lors du traitement séquentiel, de la voie intraveineuse à orale}

RÉSUMÉ : Le trailement séquentiel, qui fait passer un médicament de la voie parentérale à la voie orale. représente une stratégie efficace en termes d'économies, et peut faire diminuer la morbidité associée à l'administration intraveineuse et donner lieu à des congés hospitaliers plus précoces. Le prescripteur a le choix entre plusieurs antibiotiques oraux et il y a autant de possibilités de passer d'un médicament par voie i.v. au même médicament, ou à un autre médicament de même classe ou de classe différente, par voie orale. Il faut toutefois connaître les caractéristiques pharmacocinétiques de ces agents oraux pour que le traitement réussisse. La biodisponibilité n'est pas toujours idéale. Un schéma posologique simple favorisera l'observance thérapeutique.

A NTI-INFECTIVE DRUG EXPENDITURES IN CANADA ARE second in magnitude only to cardiovascular drugs. In the acute care hospital setting, anti-infective drugs typically account for $20 \%$ to $30 \%$ of total drug expenditures $(1,2)$.

Since the acquisition, preparation and administration costs of oral (po) anti-infective formulations are typically 10 to $40 \%$ of the cost of their parenteral (iv) alternatives (Figure 1), iv to po stepdown is being used by many hospitals as a cost containment strategy $(1,2)$.

As previously described by Louie (4), health care professionals have practised iv to po stepdown therapy in an 'uncontrolled fashion' since the availability of oral and parenteral antimicrobials. To our knowledge, the first reports describing the potential economic benefits of a formal Canadian program of oral antibiotic step-

Faculty of Pharmaceutical Sciences, University of British Columbia, Department of Pharmacy, Vancouver Hospital and Health Sciences Centre, Vancouver. British Columbia

Correspondence: Dr Peter Jewesson, Department of Pharmacy, Vancouver Hospital and Health Sciences Centre, 855 West 12 th Avenue, Vancouver, British Columbia V5Z 1M9, telephone 604-875-4077, Fax 604-875-5861, e-mail jewesson@unixg.ubc.ca 


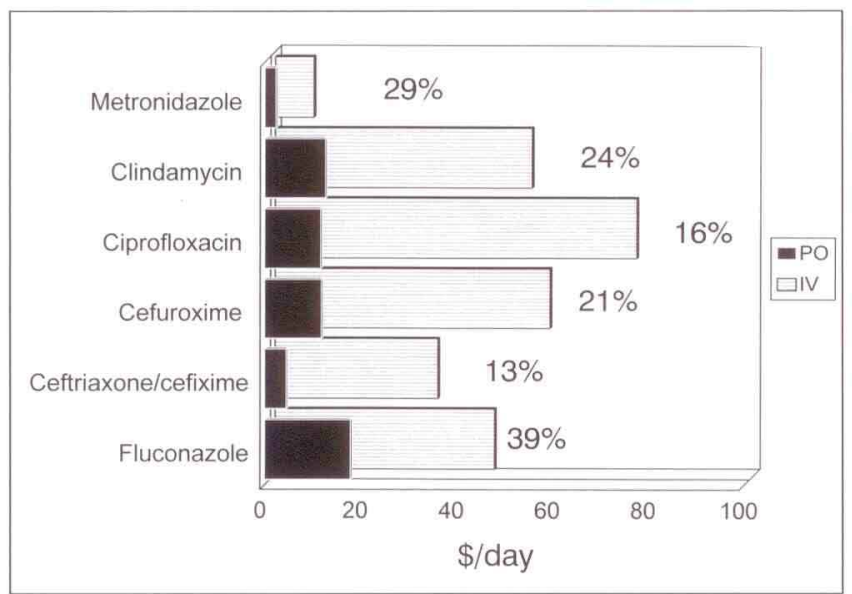

Figure 1) Relative cost of oral (po) and parenteral (iv) dosage regimens for select antibiotics. Percentage reletive cost or oral versus parenteral acquisition and delivery costs

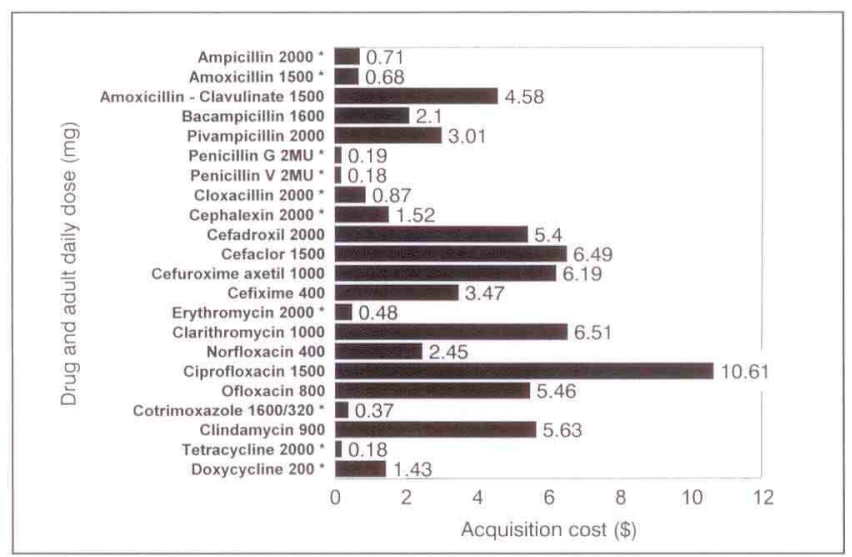

Figure 2) Examples of oral antibiotic daily costs. ${ }^{*}$ Generic brand available. BC Alpha Pharmaceutical Supplies 1993 Price Book (generic prices used when available)

down promotion were not published until 1990 when we described the preliminary results of a formal stepdown program which was initiated by the antibiotic use subcommittee of the drugs and therapeutics committee in early 1987 (5). Perhaps this reflects the 'coming of age' of this simple, yet effective, concept.

\section{TO PO STEPDOWN SCENARIO}

Stepdown from a parenteral to an oral antimicrobial agent usually follows one of four scenarios (1). In scenario 1, stepdown involves the use of the same drug in an oral dosage form which has excellent bioavailability. Drugs such as metronidazole, clindamycin and cotrimoxazole can provide concentrations in the blood following oral administration which are similar to those achieved with the parenteral dosage form. Scenario 2 involves stepdown to the same drug with a reduction in achievable systemic drug concentrations. Drugs such as ampicillin, cloxacillin and erythromycin are examples of this situation. Scenario 3 involves the stepdown to oral agents of the same or a different class which

\section{TABLE 1}

Properties of an ideal oral stepdown agent

- Same compound as the preceding intravenous drug

- Application supported by clinical data

- Multiple oral dosage forms

- $100 \%$ bioavailability

- No absorption-related drug interactions

- Well tolerated by the oral route

- Infrequent dosing regimen

- Inexpensive

have a similar spectrum of activity and good bioavailability. Conversion from ceftazidime to ciprofloxacin represents such a scenario. Finally, scenario 4 represents those situations where stepdown to another drug from an unrelated class with relatively limited bioavailability occurs. This latter scenario is typically the least desirable choice for a clinician.

\section{PROPERTIES OF THE IDEAL STEPDOWN AGENT}

General properties of the ideal oral stepdown agent are summarized in Table 1 . The ideal oral antimicrobial stepdown agent should possess properties which result in minimal disruption to the treatment course. In other words, the process of stepdown would involve the modification of one treatment parameter only, namely a change in the route of drug administration (Scenario 1). In many instances, conversion to an oral agent within the same class (eg, cefazolin to cephalexin) or of a different class (eg, cefuroxime to cotrimoxazole) should yield favourable results. Scenario 3 stepdown should be considered if the parenteral drug is not available in an oral dosage form, the oral formulation is poorly tolerated or absorbed, or there is another objective clinical rationale for this procedure. We should recognize that prescribers generally prefer to continue therapy with the same drug which was producing therapeutic results favourable enough to warrant stepdown to the oral dosage form in the first place.

The ideal stepdown agent should also have recognized activity against the pathogen(s) in question and should be supported by clinical trials demonstrating the utility of that agent for the treatment of the infection in question. To facilitate good patient compliance, the drug should be available in several dosage forms (eg, tablets, capsules, solution or suspension) to ensure stepdown is not limited by an inability to tolerate solid dosage forms.

The ideal stepdown drug should be completely absorbed with no absorption-related drug interactions (eg, tetracyclines and quinolones with antacids). Patient tolerance to the oral route of administration is a critical determinant of successful therapy. The ideal stepdown agent should have minimal side effects including gastrointestinal complaints. The ideal agent should possess a pharmacological profile which per- 
mits infrequent administration (ie, less than three doses daily). Finally, this drug must be relatively inexpensive. If a patient is to be discharged from the hospital on an oral anti-infective, the cost of therapy may now be borne directly by that individual. When efficacy and toxicity are considered equivalent, cost must be the determinant of drug choice. Figure 2 provides an illustration of the variability of drug acquisition costs for various oral antibiotic regimens in Canada. Clinicians must be cognizant of these disparities to ensure the most cost-effective regimen is prescribed.

\section{ANTI-INFECTIVE AGENTS BY DOSAGE FORM}

In Canada there are about as many anti-infective agents available with intravenous and oral dosage formulations as there are agents with an intravenous formulation only (Table 2). In addition, there are several oral agents available which could be considered as acceptable oral stepdown drugs for parenteral agents of the same or different classes. Hence, many potential iv-po combinations are possible when stepdown is being considered.

\section{BIOAVAILABILITY}

When considering switching from a parenteral to an oral agent, we introduce a new pharmacokinetic variable which was not an issue when the intravenous route of administration was being used. Bioavailability generally refers to the fraction of an oral dose which actually reaches the systemic circulation following oral ingestion (6). Drugs can differ in their rate and completeness of absorption from the gastrointestinal tract. Absorption can be influenced by patient factors such as motility of the gastrointestinal tract, blood flow to the site of absorption and the presence of various malabsorption syndromes. Drug absorption is also significantly influenced by drug properties. Dissolution of the dosage form, drug solubility and potential for a 'firstpass effect' (ie, metabolism of drug by gastrointestinal or hepatic enzymes) are several factors which affect bioavailability. Coadministration of the drug with food or other drug products (both prescription and nonprescription) can also have a significant impact on the actual bioavailability of an anti-infective under 'real life' conditions.

\section{ANTI-INFECTIVE DRUGS GROUPED BY BIOAVAILABILITY}

The bioavailability of anti-infectives ranges widely, from as low as $10 \%$ to as high as 95\% or greater. Anti-infectives can be stratified into three groups according to their average unimpeded reported bioavailability in adult patients.

Group 1 oral anti-infectives would include those agents for whom average bioavailability (typically determined by calculating the area under the concentrationtime curve (AUC) for the oral regimen and dividing this
TABLE 2

Anti-infective agents by dosage form

\begin{tabular}{lll}
\hline iv and po & iv only & po only \\
\hline Penicillin & Piperacillin & Amoxicillin \\
Ampicillin & Cefazolin & Pivampicillin \\
Cloxacillin & Cefoxitin & Bacampicillin \\
Cefuroxime axetil & Ceftizoxime & $\begin{array}{l}\text { Amoxicillin- } \\
\text { clavulanate }\end{array}$ \\
Erythromycin & Cefotetan & Cephalexin \\
Cotrimoxazole & Cefamandole & Cefaclor \\
Clindamycin & Ceftriaxone & Cefadroxil \\
Ciprofloxacin & Cefotaxime & Cefixime \\
Chloramphenicol & Ceftazidime & Clarithromycin \\
Metronidazole & Imipenem & Azithromycin \\
Doxycycline & Aminoglycosides & Norfloxacin \\
Rifampin & Vancomycin' & Ofloxacin \\
Fluconazole & Amphotericin & Tetracycline \\
Acyclovir & Ganciclovir & Itraconazole \\
& & Ketoconazole \\
\hline
\end{tabular}

iv Intravenous; po Oral; 'Oral form used for Clostridium difficile-associated diarrhea (not absorbed): ${ }^{2}$ Ampicillin prodrugs

value by the AuC for the same dose given parenterally) exceeds $80 \%$ when the drug is administered under conditions in which its absorption from the gastrointestinal tract is unimpeded (eg, not given in the presence of food or antacids). This parameter is usually determined in healthy fasting adults under controlled experimental conditions. Figure 3 illustrates some representative group 1 agents. For each drug, a minimum, maximum and average reported bioavailability is provided. The minimum value represents the estimated bioavailability when the drug is administered in the presence of food or other drug products (eg, antacids) which may interfere with absorption from the gastrointestinal tract.

There are at least 12 anti-infectives available in Canada with greater than $80 \%$ average unimpeded bioavailability. For several of these agents (eg, cefaclor, metronidazole) bioavailability is quite predictable. For others such as doxycycline and ofloxacin, bioavailability is highly dependent upon the conditions of administration. Tetracyclines form insoluble chelates with polyvalent metals including aluminum, calcium, iron, magnesium, zinc and others. Co-administration with food or drug products containing these substances can markedly reduce oral absorption. The inhibitory effect of food and milk on the absorption of doxycycline tends, however, to be less than that of tetracycline (7). The oral absorption of ofloxacin and other quinolones is also affected by the concomitant administration of divalent cations. The result can be a dramatic decrease in the peak antimicrobial blood levels achieved, as well as a marked reduction in the AUC (8).

Although bioavailability of clindamycin is generally considered very good, Gatti and colleagues (9) have recently reported findings which suggest that a reevaluation may be warranted. In a crossover design study 


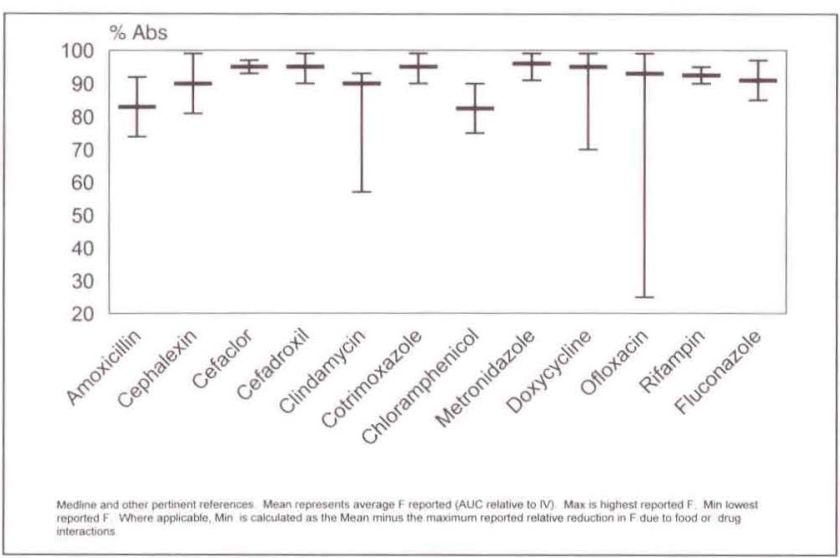

Figure 3) Group 1 oral anti-infectives (greater than $80 \%$ average unimpeded bioavailability)

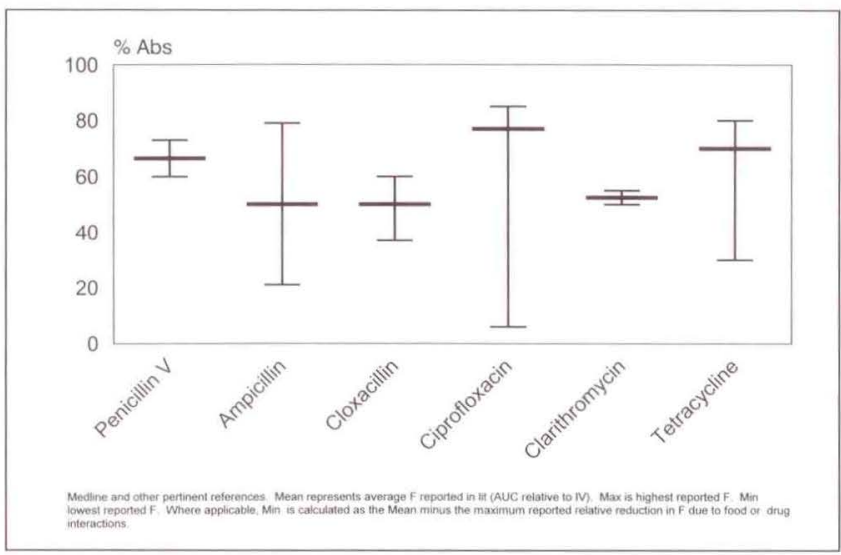

Figure 4) Group 2 oral anti-infectives (51\% to $80 \%$ average unimpeded bioavailability)

involving 16 healthy volunteers and 16 patients with AIDS, these investigators found an average absolute bioavailability (AUCPo/AUCiv) of only $53 \% \pm 14 \%$ and $75 \% \pm 20 \%$, respectively. This study is important for at least two reasons. It is the first determination of oral clindamycin bioavailability using a specific assay (ie, gas-liquid chromatography versus a bioassay) and a crossover design. Since clindamycin has microbiologically active metabolites, previous studies using bioassays would have been unable to distinguish between parent drug and active breakdown products. In addition, this study reconfirms that disease states can have an apparent influence on drug disposition. AIDS patients in this study demonstrated a higher bioavailability, higher peak blood concentration, a lower volume of distribution and reduced drug clearance compared with their healthy counterparts. The clinical significance of these findings for clindamycin is yet unknown, but it is critical to recognize that there will be inter- and intrapatient variability in drug disposition whenever one contemplates iv to po stepdown therapy.

Figure 4 shows six anti-infective agents with an average unimpeded bioavailability of 51 to $80 \%$. Again, bioavailability is quite predictable for some agents (eg, penicillin $\mathrm{V}$ and cloxacillin), while quite variable for

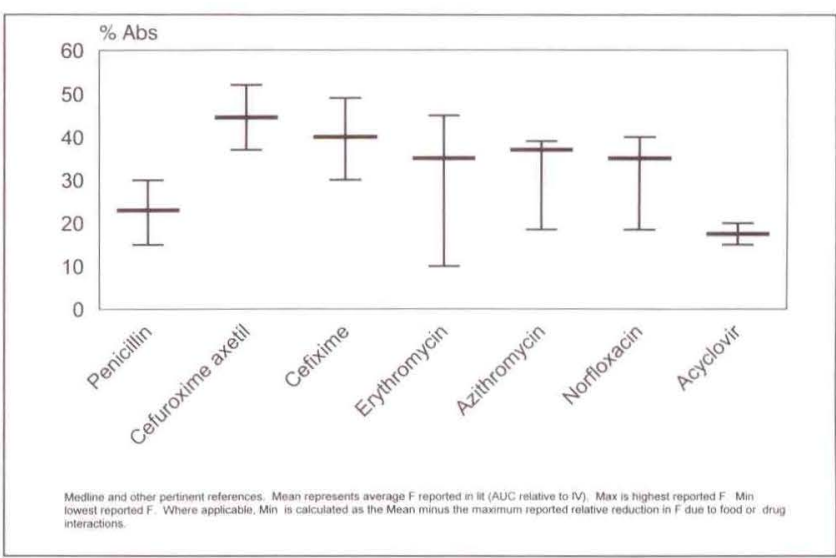

Figure 5) Group 3 oral anti-infectives (50\% or less average unimpeded bioavailability)

others (eg, ciprofloxacin and tetracycline). For these group 2 agents it is possible to achieve blood concentrations similar to that obtained with the parenteral formulation only if a larger oral dose is administered.

Group 3 oral anti-infectives are shown in Figure 5. For these agents bioavailability is so low that we generally cannot expect to achieve blood concentrations equivalent to those obtained from the parenteral formulations (when available).

Nevertheless, it is possible to stepdown from iv to po dosage forms with these agents without adversely effecting treatment course outcome. We recently reported our experience with the implementation of a standardized acyclovir prophylaxis protocol for the prevention of herpes simplex virus (HSV) infection and disease in bone marrow transplant and leukaemic patients (10). Under this protocol, patients received an acyclovir regimen of $125 \mathrm{mg} / \mathrm{m}^{2}$ iv or $600 \mathrm{mg}$ po every $6 \mathrm{~h}$ for approximately 35 days duration. Patients were assessed dally and switched from iv to po therapy if oral tolerance criteria were met. With this protocol, the incidence of parenteral therapy without oral stepdown dropped from $17 \%$ to $0 \%$ of treatment courses. A cost savings of approximately $\$ 1112.00$ per patient was realized without evidence of any negative impact on treatment course outcome.

\section{SERUM ELIMINATION HALF-LIVES OF SOME COMMON ANTI-INFECTIVE AGENTS}

The serum elimination half-life has traditionally played a role in determining the frequency of administration of the anti-infective. In general, the longer the elimination half-life, the longer the recommended interval between doses. Unfortunately, this relationship has not always been carefully considered and we have historically adopted dosing regimens which are not well supported by the pharmacological properties of the drug. For example, we have been prescribing some drugs with extended elimination half-lives (eg, metronidazole, 7 to $8 \mathrm{~h}$ ) in regimens of three to four doses daily, which is probably more often than is necessary. Con- 
versely, there are some short elimination half-life drugs (eg penicillin, $0.5 \mathrm{~h}$ ) which we prescribe at $6 \mathrm{~h}$ intervals which is equivalent to 12 -fold their half-lives. Needless to say, the optimal regimen for these agents must take into consideration the pharmacological profile of the drug including the serum elimination half-life, the existence and characteristics of active metabolites, post-antibiotic effects and other patient (eg, immunocompetence) and microbiological factors.

Although the relationship between serum elimination half-life and dosing intervals may be less important for drugs which demonstrate a concentration-dependent kill (eg, aminoglycosides), it appears to be relevant for beta lactam agents. Beta-lactams tend to exhibit a time dependent kill and it has been generally accepted that maintaining serum concentrations at or near the minimum inhibitory concentration may be most desirable (11-13).

Figure 6 illustrates the average serum elimination half-lives for various oral anti-infective agents in healthy adults with normal renal and hepatic function. The majority of oral beta-lactams have elimination halflives in the range of 0.5 to $3 \mathrm{~h}$. Quinolones tend to demonstrate elimination half-lives in the 3 to $7 \mathrm{~h}$ range, while cotrimoxazole and metronidazole exhibit the longest serum elimination half-lives of our older oral antimicrobial drugs. Newer macrolides (ie, clarithromycin and azithromycin) exhibit elimination half-lives in the 6 to $12 \mathrm{~h}$ range. Azithromycin actually undergoes extensive tissue distribution and the terminal serum elimination half-life is dependent on the time interval being examined. When serum concentrations are assessed during the first $24 \mathrm{~h}$ following oral administration, the serum elimination half-life ranges from 11 to $14 \mathrm{~h}$. When concentrations are assessed for a longer period of time (eg, 12 days), the serum elimination half-life is approximately five days (14).

\section{PHARMACOKINETIC CHARACTERISTICS OF ORAL CEPHALOSPORINS}

A comparison of the pharmacokinetic characteristics of oral cephalosporins is shown in Table 3 . There are five oral cephalosporins currently available in Canada. This includes two first generation agents (cephalexin and cefadroxil), two second generation agents (cefaclor and cefuroxime axetil) and one third generation agent (cefixime). These designations have been made based upon the relative spectrum of antimicrobial activity of these agents. While the oral absorption of cephalexin, cefadroxil and cefaclor is very good (group 1 drugs), cefuroxime axetil and cefixime demonstrate generally poor absorption from the gastrointestinal tract (group 3 drugs). Cefuroxime axetil is rapidly hydrolyzed to cefuroxime by nonspecific esterases in the intestinal mucosa and blood. The absorption of this drug is actually improved by coadministration with food. Cefixime has the longest serum elimination half-life of all available

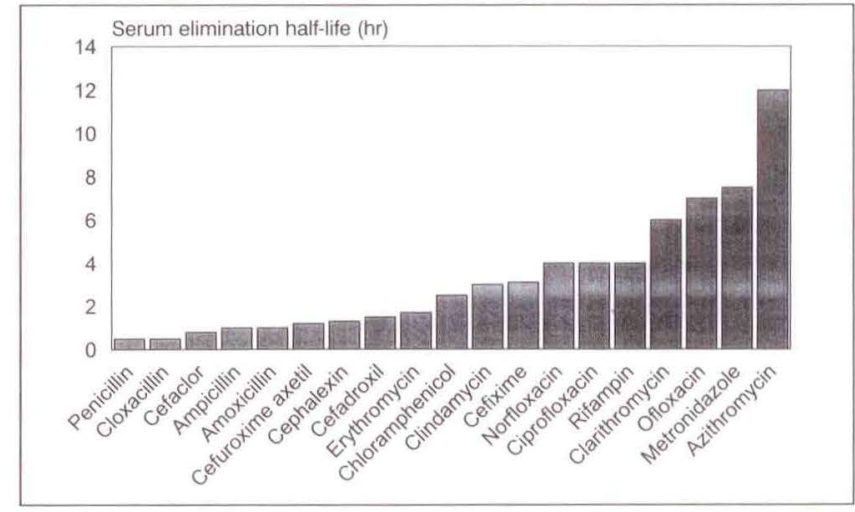

Figure 6) Serum elimination half-life of various oral antimicrobials

oral cephalosporins and can be administered once or twice daily. Food and antacids do not appear to influence the bioavailability of this drug (15).

The newer (and as of yet unavailable) oral cephalosporins possess pharmacokinetic characteristics not too dissimilar to those already available (16). Cefpodoxime proxetil and cefetamet pivoxil demonstrate absorption problems similar to cefuroxime axetil and cefixime. None of the never agents provide serum concentrations significantly higher than the older agents and none are in the range of that achievable with parenteral formulation. However, the in vitro activity of these agents against many of our common pathogens is often superior to earlier drugs. The serum elimination half-lives of these newer agents are similar to existing agents. Janknegt and van der Meer (17) recently reviewed these agents and identified that the period per $24 \mathrm{~h}$ during which the serum concentration exceeds the minimum inhibitory concentration (MIC50 in this case) for various pathogens is longer for newer oral cephalosporins, such as cefpodoxime and cefetamet, than older agents, such as oral or parenteral cefuroxime. Activity against Staphylococcus aureus, however, is limited for these newer agents and clinicians must be cautious if contemplating stepdown from a parenteral second or third generation cephalosporin. Whether the new oral cephalosporins will have a significant clinical advantage over our existing oral stepdown armamentarium will need to be confirmed in carefully controlled trials. Perhaps future investigation should not only include the identification of better tolerated agents with improved activity against clinically relevant pathogens, but also investigation into the production of sustained release oral beta-lactam formulations which can be taken once daily and produce predictable, constant blood concentrations above the MIC of these pathogens.

\section{COMPLIANCE AND TREATMENT REGIMEN COMPLEXITY}

Probably one of the most significant determinants of successful oral anti-infective therapy is patient compliance. The best drug in the world is useless if the patient 
TABLE 3

Pharmacokinetic characteristics of oral cephalosporins

\begin{tabular}{|c|c|c|c|c|}
\hline Agent/dose & $\%$ absorption & $C \max (\mathrm{mg} / \mathrm{L})$ & $\mathrm{T} 1 / 2(\mathrm{~h})$ & PPB (\%) \\
\hline Cephalexin 500 mg & $>90$ & $15-20$ & $0.5-1.0$ & 10 \\
\hline Cefadroxil 500 mg & $>90$ & $12-18$ & $1.0-1.5$ & 20 \\
\hline Cefaclor $500 \mathrm{mg}$ & $>90$ & $15-20$ & $0.5-1.0$ & 23 \\
\hline Cefprozil $500 \mathrm{mg}$ & $>90$ & $7-11$ & $1.0-1.5$ & 65 \\
\hline Loracarbef $400 \mathrm{mg}$ & 90 & $15-20$ & $1.0-1.5$ & 25 \\
\hline Ceftibuten 200 mg & 80 & $9-12$ & $1.5-2.5$ & 70 \\
\hline Cefpodoxime proxetil $400 \mathrm{mg}$ & $40-60$ & $4-7$ & $2.0-3.0$ & 40 \\
\hline Cefetamet pivoxil $500 \mathrm{mg}$ & $30-50$ & $3-5$ & $2.0-2.5$ & 25 \\
\hline
\end{tabular}

Data represents typical adult normal renal function values derived from Smith GH. Drug Intell Clin Pharmacy 1990, Lode H et al. Drugs 1994, and others. PPB Plasma protein binding

is unable or unwilling to adhere to the prescribed dosing schedule. Using microprocessors in the caps of pill bottles, Cramer and associates (18) demonstrated that compliance rates were $81 \%$ with a twice daily regimen versus 39\% with a four times daily schedule. We should keep this observation in mind when prescribing iv to po stepdown, regardless of who (ie, patient or nurse) is responsible for administering the medication.

\section{SUMMARY}

Parenteral to oral stepdown therapy represents an effective cost containment strategy which can minimize

\section{REFERENCES}

1. Jewesson P. Cost-effectiveness and value of an IV switch. PharmacoEconomics 1994;5(Suppl 2):20-6.

2. Kunin CM. Problems in antibiotic usage. In: LA Mandell, et al (eds). Principles and Practice of Infectious Diseases, 3rd edn. Edinburgh: Churchill Livingston, 1990:427-34.

3. Quintiliani R, Cooper BW, Briceland LL, Nightingale CH. Economic impact of streamlining antibiotic administration. Am J Med 1987;82(Suppl 4A):391.

4. Louie TJ. Intravenous to oral stepdown antibiotic therapy: another cost effective strategy in an era of shrinking health care dollars. Can J Infect Dis 1994;5(Suppl C):45C-50C.

5. Bunz D. Frighetto L, Gupta S, Jewesson P. Simple ways to promote cost containment. Drug Intell Clin Pharmacy, Ann Pharmacother 1990:24:546.

6. Gibaldi M, Perrier D. Pharmacokinetics, 2nd edn. Revised and Expanded. New York: Marcel Dekker Inc, page 411.

7. Tatro DS, eds. Drug Interactions Facts. St Louis: Wolters Kluwer Co, 1994.

8. Hansten PD, Horn JR, Koda-Kimble MA, Young LY, eds. Drug Interactions and Updates Quarterly. Vancouver, Washington:Applied Therapeutics Inc, 1993.

9. Gatti G, Flaherty J, Bubp J, White J, Borin M, Gambertoglio J. Comparative study of bioavailabilities and pharmacokinetics of clindamycin in healthy volunteers and patients with AIDS. Antimicrob Agents Chemother 1994;37:1 137-43.

10. Rayani SA, Reesor Nimmo CJ, Frighetto L, et al. intravenous therapy associated morbidity and may facilitate earlier hospital discharge. Several oral anti-infectives are available to the prescriber and there are as many opportunities to stepdown to the same agent as there are to other drugs of the same class or other classes. Recognition of the pharmacokinetic characteristics of these oral agents is essential to successful therapy. Good bioavailability may not always be assured. A simple regimen will promote compliance. A quote from Plateus (BC 254-184) reads: “... in everything the middle course is best; all things in excess bring trouble to men...", a philosophy which should probably apply to iv to po stepdown as well.

Implementation and evaluation of a standardized herpes simplex virus prophylaxis protocol on a leukemia/bone marrow transplant unit. Ann Pharmacother 1994;28:852-6.

11. Drusano GL. Human pharmacodynamics of beta-lactams, aminoglycosides and their combination. Scand J Infect Dis 1991:74:235-48.

12. Schentag JJ. Correlation of pharmacokinetic parameters to efficacy of antibiotics: relationships between serum concentrations, MIC values and bacterial eradication in patients with gram-negative pneumonia. Scand J Infect Dis 1990;74(Suppl):218-34.

13. Drusano GL. Role of pharmacokinetics in the outcome of infections. Antimicrob Agents Chemother 1988;32:289-97.

14. Foulds G, Shepard RM, Johnson RB. The pharmacokinetics of azithromycin in human serum and tissues. J Antimicrob Chemother 1990;5(Suppl 3A):73-82.

15. Leggett NJ, Caravaggio C, Rybak MJ. Cefixime. Drug Intell Clin Pharmacy, Ann Pharmacother 1990;24:489-95.

16. Lode H, Fassbender M, Schaberg T, Borner K, Koeppe P. Comparative pharmacokinetics of the new oral cephalosporins. Drugs 1994;47(Suppl 3):10-20.

17. Janknegt R, van der Meer JWM. Sequential therapy with intravenous and oral cephalosporins. J Antimicrob Chemother 1994;33:169-77.

18. Cramer JA, Mattson RH, Prevey ML, Scheyer RD, Ouellette VL. How often is medication taken as prescribed? A novel assessment technique. JAMA 1989:261:3273-7. 


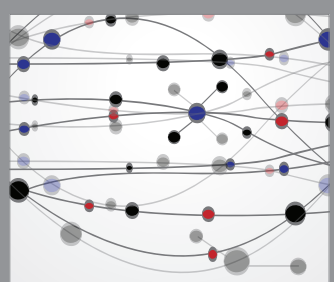

The Scientific World Journal
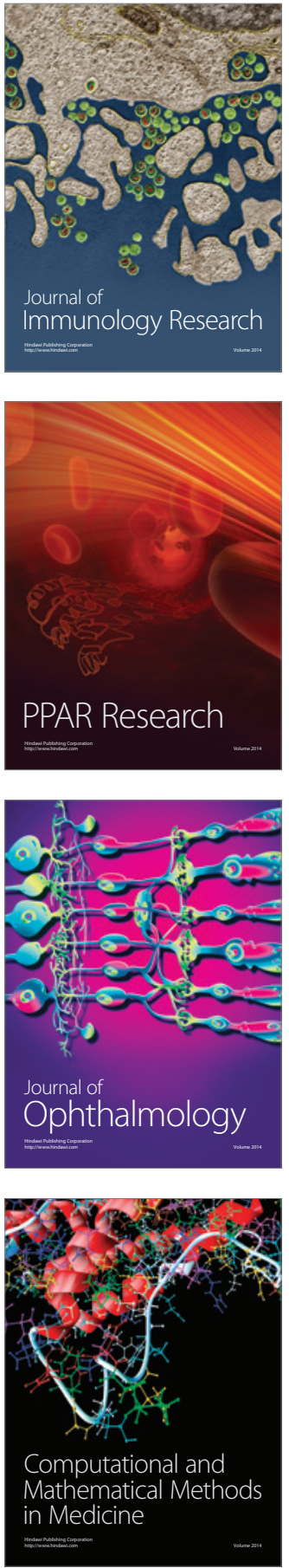

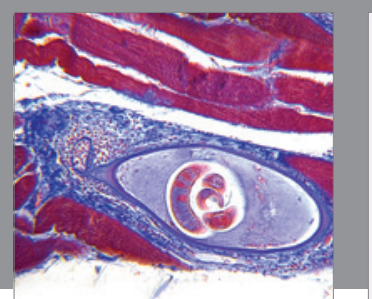

Gastroenterology Research and Practice

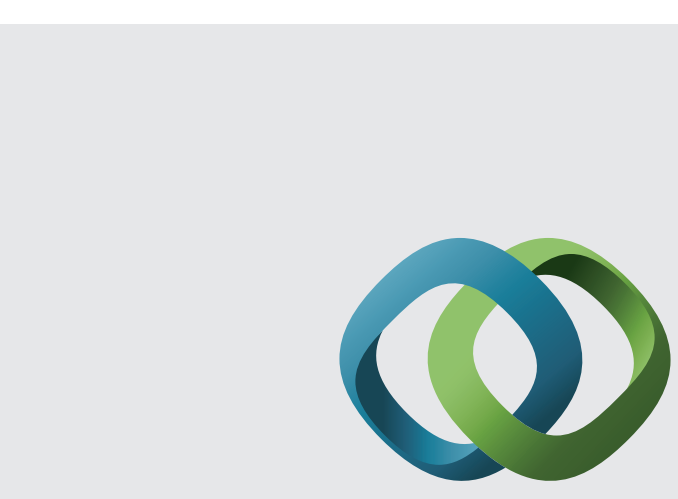

\section{Hindawi}

Submit your manuscripts at

http://www.hindawi.com
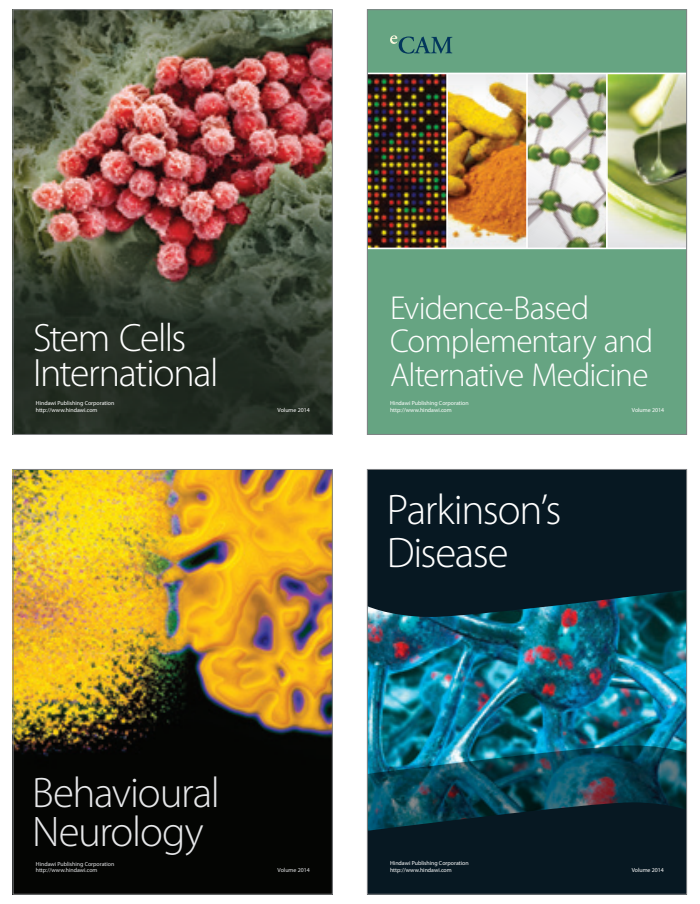
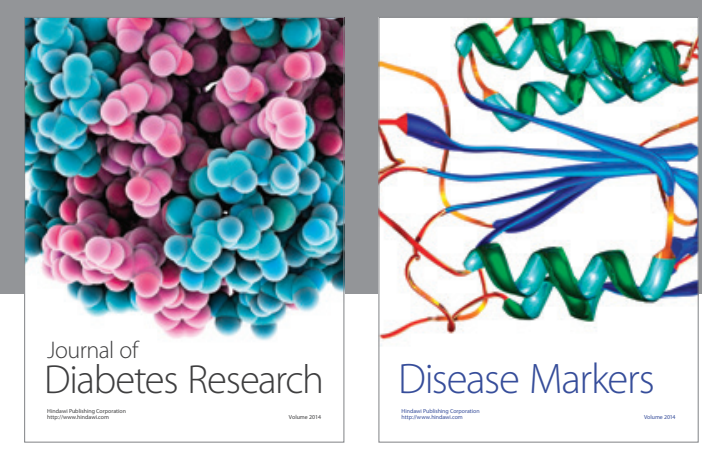

Disease Markers
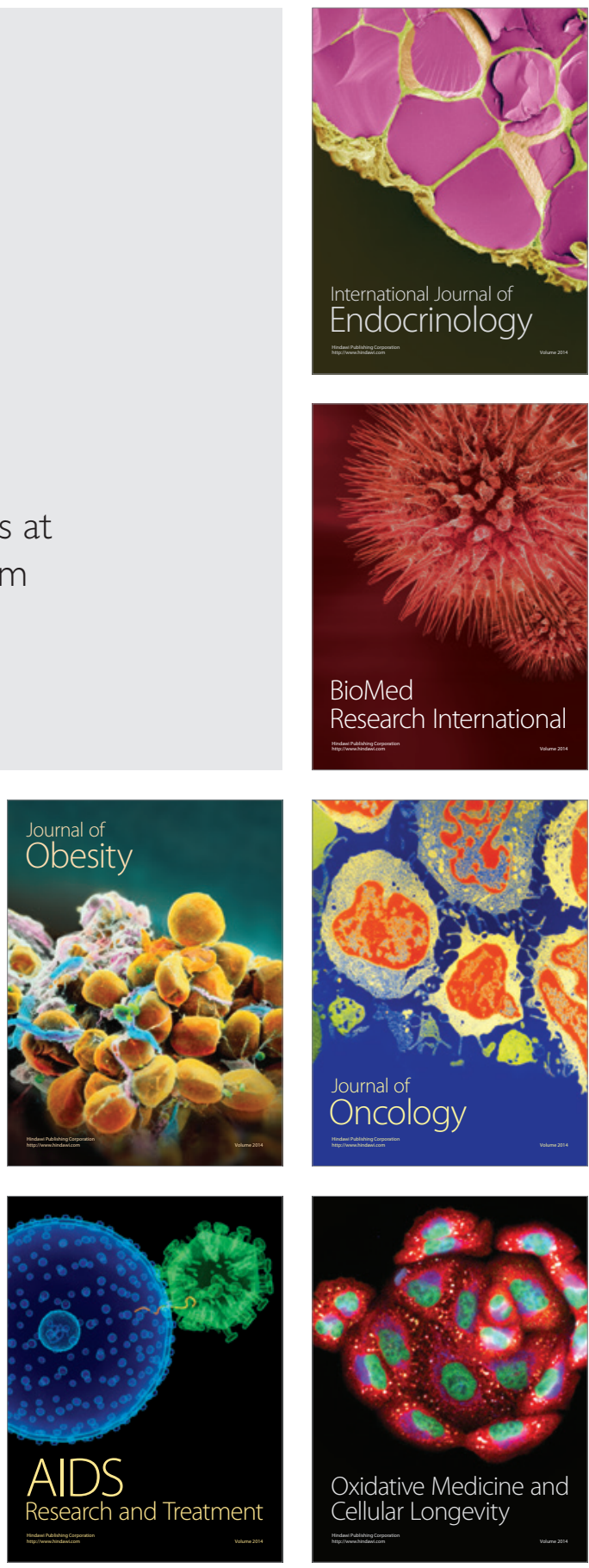